\title{
MicroRNAs as monitoring markers for right-sided heart failure and congestive hepatopathy
}

\author{
Ruxandra Florentina Ionescu ${ }^{1}$, Sanda Maria Cretoiu ${ }^{2 *}$
}

\section{Author Affiliations:}

1. Department of Cardiology I,

Central Military Emergency University Hospital Dr. Carol Davila, Bucharest, Romania

2. Department of Morphological Sciences, Cell and Molecular Biology and Histology, Carol Davila University of Medicine and Pharmacy, Bucharest, Romania

\section{ABSTRACT}

The last decades showed a worrying increase in the evolution of cardiovascular diseases towards different stages of heart failure $(\mathrm{HF})$, as a stigma of the western lifestyle. MicroRNAs (miRNAs), non-coding RNAs, which are approximately 22-nucleotide long, were shown to regulate gene expression at the post-transcriptional level and play a role in the pathogenesis and progression of HF. miRNAs research is of high interest nowadays, as these molecules display mechanisms of action that can influence the course of evolution of common chronic diseases, including HF. The potential of post-transcriptional regulation by miRNAs concerning the diagnosis, management, and therapy for HF represents a new promising approach in the accurate assessment of cardiovascular diseases. This review aims to assess the current knowledge of miRNAs in cardiovascular diseases, especially right-sided heart failure and hepatomegaly. Moreover, attention is focused on their role as potential molecular biomarkers and more promising aspects involving miRNAs as future therapeutic targets in the pathophysiology of $\mathrm{HF}$.

KEYWORDS: miRNAs, microRNAs, heart failure, cardiac insufficiency, heart remodeling, hepatomegaly, congestive hepatopathy.

\author{
* Corresponding Author: \\ Sanda Maria Cretoiu, \\ Department of Morphological \\ Sciences, Cell and Molecular \\ Biology and Histology, Carol \\ Davila University of \\ Medicine and Pharmacy, \\ Bucharest, Romania. \\ E-mail: sanda@cretoiu.ro
}

DOI

10.25122/jml-2021-0071

Dates

Received: 3 February 2021

Accepted: 30 March 2021

\section{INTRODUCTION}

Cardiovascular diseases, heart failure (HF) included, result from numerous interactions from diverse genomic, genetic, environmental factors and lifestyle. MicroRNAs (miRNAs) display significant roles in cardiovascular pathophysiology and may even serve as diagnostic and prognostic markers for some conditions. The roles of miRNAs in signaling pathways are rapidly extending. A highly desired challenge for the function of miRNAs in HF is the possibility of using miRNAs as response assessment to therapy and even as a screening method. It is daring to hope that in the future, miRNA-mediated clinical interventions for the prevention, diagnosis, and even treatment of $\mathrm{HF}$ will be possible [1].

Heart failure, one of the leading causes of mortality and morbidity worldwide, is defined by the American Heart Association and American College of Cardiology as a complex clinical syndrome that can result from any structural or functional cardiac disorder that impairs the ability of the ventricle to fill with or eject blood". Regarding signs and symptoms, the most important ones are orthopnea, paroxysmal nocturnal dyspnea, lower extremity edema, and fatigue. Based on the ejection fraction (EF) of the left ventricle, there can be patients with $\mathrm{HF}$ with preserved $\mathrm{EF}$ and patients with $\mathrm{HF}$ with reduced $\mathrm{EF}$ [1]. HF most often occurs as the last stage of decompensation of many pre-existing disorders, such as chronic high blood pressure, coronary artery disease, myocardial infarction, myocarditis, mitral regurgitation by overload, drug abuse, or as a result of chemotherapy. Some other factors such as congenital heart defects, abnormal heart valves, diabetes, sleep apnea, and alcohol abuse can also contribute [2]. 


\section{JOURNAL of MEDICINE and LIFE}

Left-sided heart failure appears when the heart's left ventricle can no longer pump enough blood; therefore, pressure and volume in the pulmonary veins increase, resulting in pulmonary congestion, shortness of breath, paroxysmal nocturnal dyspnea, orthopnea, fatigue, weakness, and reduced ability to exercise. Right-sided heart failure happens when the the right ventricle is not strong enough to pump blood into the pulmonary circulation. As a result, the high venous pressure leads to ascites, hepatosplenomegaly, dilated jugular veins, weight gain, and gastrointestinal distress [3]. miRNAs represent a new set of endogenous gene regulators, which usually include about 22 nucleotides [4], organized as single-stranded RNAs (ribonucleic acid), which shape the expression of most messenger RNAs (mRNAs) [5]. They represent a category of non-protein-coding small RNA molecules with significant roles in regulating gene expression [6] at a post-transcriptional level [4]. miRNAs are essential for a proper foundation and adequate performance of all biological processes in humans. Therefore, any disruption of miRNAs functions results in a potential pathophysiological effect [7]. miRNAs are mostly transcribed from DNA sequences into primary miRNAs, transformed into precursor miRNAs, and consequently mature miRNAs. Usually, miRNAs cooperate with the 3' untranslated region of the target messenger RNA (mRNA), leading to mRNA degeneration and translational repression. miRNAs are also capable of triggering translation or modulating transcription [6]. miRNAs display a variety of actions, which depend on their location, their amount, target mRNAs, and compatibility of miRNA-mRNA cooperation [6].

Increasingly thought-provoking results have been done since the discovery of miRNAs in 1993 by Lee et al. [8]. As a consequence, one reveals for miRNAs increasing importance as diagnostic, prognostic and follow-up indicators for a multitude of conditions [9-11] and are seen as future markers for noninvasive screening $[12,13]$. From the hugeness of information related to miRNAs, this review aims to point out the most important discoveries related to their usefulness in heart failure, with greater emphasis on right heart failure accompanied by hepatomegaly.

\section{THE BIOLOGY OF MIRNAS}

microRNAs have long been shown to control numerous biological processes, even tumorigenesis [14]. Interestingly, miRNAs are widespread in the human body, either in circulating fluids or extracellular sites [9], and play significant roles in both the normal function of systems, but also in the pathogenesis of diseases [15]. miRNAs are protected from the ribonucleic acid degradation enzyme by being included in lipoprotein complexes [9] (argonaute 2-AGO2 [5, 16, 17], high-density lipoprotein - HDL [18-20], and nucleophosmin 1 [6, 21-23] or in extracellular vesicles [24-26] or miRNA 3' end methylation or 3' end nucleotide addition [9, 27]. Intracellular miRNAs are known to regulate gene differentiation, proliferation, and apoptosis [4]. Circulating miRNAs have been detected in plasma, serum [22, 28], cerebrospinal fluid [29], saliva [16], breast milk [30], urine, tears, colostrum, peritoneal fluid, bronchial lavage, seminal fluid [31], ovarian follicular fluid [32]. Circulating miRNAs are studied as potential circulating biomarkers and therapeutic targets [33] for specific diseases due to their high extracellular stability [1]. Extracellular miRNAs can also be identified in vesicles (exosomes [11, 25, $34]$ microvesicles and apoptotic bodies) [16, 35, 36]. Extracellular miRNAs can act as autocrine, paracrine, or endocrine controllers of cellular activities [35]. Thus, miRNAs can be considered as having hormone-like actions [6].

Furthermore, studies point to the direction of miRNAs' roles in stem cell functions [37]. miR-1 was proved to influence skeletal and cardiac muscle development [37], miR-155 functionally inhibits the hematopoietic differentiation [38], miR-221, and miR-222 block erythropoiesis [39], miR-223 promotes granulopoiesis [40] and induces T cell lineage [37, 41]. miR-9/9, miR-22, miR-124a and miR-125b were linked to astrocyte genes suppression [42], miR-206 promotes myoblast fusion [43], miR-133 blocks mesenchymal stem cell differentiation [44], while miR-181 induces B cell differentiation [41].

\section{PERSONALIZED MEDICINE IN HEART FAILURE}

\section{microRNAs as diagnostic markers in HF}

miRNAs can be released into extracellular fluids; therefore, they can be identified as biomarkers for a multitude of disorders [6, 45-47]. Histologically, the occurrence of HF is a consequence of tissue remodeling that occurs as the cardiovascular disease progresses. Ventricular remodeling in HF is based on numerous processes, the most important of which are cardiomyocyte hypertrophy, excessive fibrosis of interstitial tissue, decreased angiogenesis and, last but not least, apoptosis [48]. Navickas et al. reviewed 19 studies and aimed to determine possible miRNAs that could be used as plasma or serum biomarkers for diagnosis or prognosis for patients suffering from atherosclerosis, coronary artery disease, and acute coronary syndrome [49], concluding that miR-133a/b (5 studies), miR-208a/b (6 studies), and miR-499 (7 studies) were important markers for diagnosis and/or prognosis of cardiovascular diseases. Another conclusion was that miR-1 and miR-145b could be biomarkers for the acute coronary syndrome, while miR-1 has greater sensitivity for all types of acute myocardial infarction. miR-145 was found to be relevant for ST-segment elevation myocardial infarction and also indicates poor repercussions of acute myocardial infarction [49]. Myocardial hypertrophy represents the major adaptive process leading to HF. Studies are generally performed on animal models and have shown that there are several miRNAs, either up-regulated or down-regulated, which are involved in cardiomyocyte hypertrophy. Cardiac hypertrophic pathways were shown to be promoted by the miR-208 family, miR-212/132, miR-23, and miR-199, while miR-1, miR-133, miR-378, miR-185, and miR-155 had anti-hypertrophic effects [50-58]. What is more, miR-1, miR-133, miR-208, and miR-499 were identified to command the identity of cardiomyocytes [59]. miR-133 in inflammatory microvesicles was associated with metabolic and cardiovascular diseases [49], alongside the let-7 family, miR-17/92 


\section{JOURNAL of MEDICINE and LIFE}

family, miR-21, miR-29, miR-126, miR-133, miR-146, and miR-155 [60]. miR-126 anticipated the appearance of cardiovascular events in patients who have stable coronary artery disease [61]. Non-diabetic patients with stable coronary artery disease displayed a considerable decline of miR-126 in circulating microvesicles [62].

Cardiac fibrosis, as a consequence of the healing process, especially after myocardial infarction, leads to a hampered myocardial contractile function and represents the major cause for cardiac arrhythmias. Therefore, monitoring fibrosis is a key element, and different miRNAs involved in collagen metabolism were studied. Several pro-fibrotic ones include miR-21, miR-15, and miR-1. However, the results of many studies are controversial, at least for miR-21, which was seen as a promising drug target [63-65]. On the other hand, miR-29, miR-133, miR-26a, miR-24, miR-19a-3p/19b-3p, and miR-101a were described as antifibrotic miRNAs, being associated with the regulation of genes encoding for extracellular matrix connective tissue fibers and elements [66, 67].

The angiogenesis process is critical for myocardial repair; therefore, the maintenance of an appropriate local vascularization is the key element in preventing the hypertrophy of the working cardiomyocytes. Moreover, fibrosis accompanies reduced capillaries in tissue, and therefore, new miR-based therapies promoting angiogenesis appear nowadays as promising possibilities in the prevention of $\mathrm{HF}$ [68]. The primary miRNAs with anti-angiogenic function are depicted in several studies, and some can be named as more important: miR-17-92, miR-126, miR-24, miR-214, and miR-34. Others seem to induce angiogenesis, i.e., miR-210, by releasing angiogenic factors [69-71]. miR-1, along with miR-133, were identified to have roles in endothelial function and angiogenesis. miR-133 was also linked to restraining cardiac hypertrophy. miR-133, together with miR-145, can influence vascular smooth muscle cell differentiation, while miR-145 alone contributes to plaque stabilization through facilitating vascular smooth muscle and endothelial communication [49]. Furthermore, miR-17, miR-18, miR-19, and miR-20 proved to possess anti-angiogenic functions [72], while miR-92a was mostly up-regulated in ischemic conditions and inhibited angiogenesis by acting on the pro-angiogenic factor integrin a5 (ITGA5) [73].

Cardiac cell death, also known as apoptosis, also represents a key event in the progression of any cardiovascular condition towards chronic HF. The mechanism underlying this programmed cell death is still poorly understood [74]. However, several miRNAs were discovered as main contributors in the pro-apoptotic process: miR-133, miR-21, miR-30 family, miR-138, miR-499 and miR-181c [75-78]. Many of the factors listed above as being involved in the pathogenesis of HF are also involved in other processes that will ultimately contribute to the development of HF. In the review conducted by Navickas et al., miR-1, miR-133, miR-499 display roles in apoptosis, while miR-1, miR-133, miR-145, miR-208, miR-499 in the differentiation of cardiac myocytes. Their part in these mechanisms could be enlightened by monitoring the shared RNA targets such as cyclin-dependent kinase inhibitor 1A (or p21), ETS proto-oncogene 1 , fascin actin-bundling protein 1, hyperpolarization-activated cyclic nucleotide-gated potassium channel 4, insulin-like growth factor 1 receptor LIM and SH3 protein 1, purine nucleoside phosphorylase and transgelin 2 [49].

The overall conclusion is that plasma and/or serum levels of miR-1, miR-133a/b, miR-145, miR-208a/b, and miR-499(a) point into the direction of the most promising diagnostic features for cardiovascular diseases [49]. The important review by Navickas $e t$ al. revealed that miRNAs display key roles in the pathogenesis of cardiovascular diseases, supporting their applicability as diagnostic features [49]. The outcome of the study conducted by $\mathrm{Li}$ et al. was that some cardiac fibroblast-derived miRNAs (miR-660-3p, miR-665, and miR-1285-3p) were up-regulated in both heart and plasma in chronic HF, correlated with left ventricle EF and HF severity [79]. Furthermore, concentrations of circulating miR-30c and miR-181c were found to be lower in patients with chronic $\mathrm{HF}$. Li and colleagues concluded that miR-660-3p, miR-665, and miR-1285-3p possess high accuracy for diagnostic purposes [79]. Concerning the relationship between miRNAs and atherosclerosis, it was suggested that while some miRNAs may play a role in atherosclerosis in certain territories, others are engaged in general mechanisms of atherosclerosis throughout the human body [47]. For example, a recurrent pattern was found in patients with carotid atherosclerosis: upregulation of miR-21 (favors angiogenesis, controls vascular smooth cell apoptosis and proliferation) and downregulation of miR-30, miR-126, and miR-221-3p. miR-21 has also been noted to be in high quantities in patients with coronary artery disease [47, 80].

Liver disease caused by HF is also known as „,cardiac hepatopathy”. One of its main forms is congestive hepatopathy $(\mathrm{CH})$, consisting of venous congestion associated with right-sided HF. The chain of events determined by chronic passive congestion is represented by sinusoidal hypertension, centrilobular fibrosis, cirrhosis, and even carcinogenesis (hepatocellular carcinoma) [81]. In another study, miR-122, the predominant miRNA in the liver [82], was indicated to be essential for liver homeostasis, while its loss resulted in promoting liver steatosis, inflammation, fibrosis, and even carcinogenesis [82-84]. Abu-Halima and colleagues conducted a study on liver fibrosis/cirrhosis in univentricular heart patients, with or without Fontan palliation. Univentricular heart disease (UHD) is a rare congenital heart disorder consisting of one ventricle, implying volume overload of the unique ventricular cavity and systemic venous congestion. Fontan procedure is the palliative intervention that can connect both caval veins to the pulmonary artery, conducting systemic venous blood directly into the pulmonary circulation.

Systemic venous congestion associated with this condition results in liver congestion, liver fibrosis and, later on, cirrhosis [85]. There were no specific miRNAs linked to the beginning or progression of liver fibrosis for patients with UHD. However, the study aimed to determine miRNAs that could point into the direction of important liver fibrosis in UHD patients [85]. miR-29b-3p and miR-29c-3p proved to be best related to the Model for End-stage Liver Disease (MELD)-Albumin and Albumin-Bilirubin (ALBI) scores, being in higher concentrations in patients with MELD-Albumin scores over 11 and ALBI scores over -2.6, indicating fibrosis or cirrhosis of the liver [85]. These miRNAs were also elevated in patients with UHD, especially with liver congestion and incomplete or no Fontan palliation, compared to healthy individuals. miR-29c-3p was significantly correlated with liver congestion (collapsibility index of the inferior vena cava less than 0.15), severe liver dysfunction (total bilirubin level and platelet count), and also had prognostic value [85]. 


\section{JOURNAL of MEDICINE and LIFE}

Between acute HF patients and healthy individuals, low levels of miR-103, miR-142-3p, miR-30b, and miR-342-3p [86] were noted, alongside high levels of miR-499 for acute HF [87], [88]. Tijsen et al. found out that miR-423-5p could distinguish between healthy individuals and HF patients and also between HF and other causes of dyspnea [88, 89]]. Three studies also showed different levels of circulating miRNAs in $\mathrm{HF}$ with reduced ejection fraction compared to HF with preserved ejection fraction [86, 88, 90, 91]. Regarding the prognostic value of miRNAs, low levels of miR-126 were correlated with cardiovascular death in ischemic HF patients, while elevated levels of miR-508a-5p were associated with cardiovascular death in non-ischemic HF patients [92]. miR-18a-5p and miR-652-3p were decreased in HF hospitalized patients, being predictive for 180-day mortality [93]. In order for miRNAs to be used as biomarkers for the diagnosis of HF, they have to outperform natriuretic peptides or have additive value [88].

\section{microRNAs: Response to therapy biomarkers or therapeutic targets?}

Cardiac fibrosis is a fundamental process in the evolution of HF. Zhou et al. pointed out that miR-503 was up-regulated in mouse heart subjects, supporting its role in the development of heart fibrosis. By promoting angiotensin II-induced fibrosis, miR-503 represents a prospective therapeutic target for decreasing cardiac fibrosis in HF patients [94]. The research conducted by Sygitowicz et al. pointed out that miR-29 family members (miR-29a and miR-29b), miR-150, and miR-30a-5p regulate basic processes linked to left ventricular dysfunction and heart failure after acute myocardial infarction. Moreover, these molecules could represent possible therapeutic targets during disease progression [95].

It is known that cardiac resynchronization therapy (CRT) is associated with improved performance and survival in patients with HF and electromechanical dyssynchrony. The research conducted by Marfella et al. included 81 patients with severe left ventricle dysfunction, significant intraventricular and interventricular dyssynchrony, and severe left ventricle dilatation. The advantages of CRT regarding left ventricle functional recovery and cardiac remodeling were linked to modulating circulating miRNAs patterns responsible for cardiomyocyte hypertrophy, fibrosis, and apoptosis for patients with HF - New York Heart Association (NYHA) classes III or IV. miRNAs associated with HF can be regulated by CRT, thus leading to favorable outcomes of heart function [96]. In animal studies, circulating levels of miR-16, miR-20b, miR-93, miR-106b, miR-223, and miR-423-5p were elevated in the subjects with hypertension-induced HF. After administering antimir for miR-208a or angiotensin-converting enzyme inhibitor, miRNAs, except for miR-19b, returned to normal levels in about eight weeks, thus proving that circulating miRNAs have a dynamic potential response to treatment [88]. In order to be sure about the possible response-to-therapy prediction, other extensive cohort studies need to be conducted. The roles of miRNAs are definitely of high interest for future therapies and follow-up in HF patients.

\section{CONCLUSION}

Studies on the importance of miRNA in heart failure are becoming more numerous. Up to date, several publications describe the involvement of miRNAs in various phases of heart failure evolution. However, many issues, such as the origins of many of the circulating miRNAs, remain to be determined. Expression abnormalities of many miRNAs have been associated with different forms of heart failure, and several miRNAs were described as correlated with cardiac hypertrophy and fibrosis. Animal studies revealed that miRNAs levels and functions could be controlled both by genetic and pharmacological means, and anti-miRNA oligonucleotides can control the effects of miRNAs. The role of miRNAs as possible therapeutic targets in the treatment of heart failure emerged from ameliorated cardiac function after pharmacological interventions [97, 98]. Thereupon, it is likely that serum and/or myocardial miRNA profiling could represent biomarkers for HF severity and therapeutic response. In the future, advances in genetics and pharmacology research will hopefully lead to cardiac-specific miRNA-based therapies (miR-mimics, antagomiRs), consequently improving outcomes of HF patients.

\section{ACKNOWLEDGMENTS}

\section{Conflict of interest}

The authors declare that there is no conflict of interest.

\section{REFERENCES}

1. Wang $\mathrm{H}$, Cai J. The role of microRNAs in heart failure. Biochimica et Biophysica Acta Mol. Basis Dis., 2017; doi: 10.1016/j.bbadis.2016.11.034

2. Johnson FL. Pathophysiology and Etiology of Heart Failure Cardiology Clinics, 2014. doi: 10.1016/j.ccl.2013.09.015

3. Types of heart failure. InformedHealth 2018. Cologne, Germany: Institute for Quality and Efficiency in Health
Care (IQWiG); https://www.ncbi.nlm.nih.gov/books/ NBK481485/?report=classi. dHealth.org

4. Xia T, Li J, Cheng H, Zhang C, Zhang Y. Small-Molecule Regulators of MicroRNAs in Biomedicine. Drug Dev. Res., 2015 , doi: $10.1002 / \mathrm{ddr} 21271$.

5. Sheu-Gruttadauria J, Pawlica P, Klum SM, Wang S, Yario TA, Schirle Oakdale NT, Steitz JA, McRae IJ. Structural Basis for Target-Directed MicroRNA Degradation. Mol. Cell, 2019, 75 (6): 1243-1255

6. O'Brien J, Hayder H, Zayed Y, Peng C. Overview of MicroRNA Biogenesis, Mechanisms of Actions, and
Circulation. Front Endocrinol (Lausanne). 2018.

doi: $10.3389 /$ fendo 2018.00402

7. Zaporozhchenko IA, Rykova EY, Laktionov PP. The Fundamentals of miRNA Biology: Structure, Biogenesis, and Reguantar or https://doi.org/10.1134/S106816202001015X

8. Lee RC, Feinbaum RL, Ambros V. The C. elegans heterochronic gene lin-4 encodes small RNAs with antisense complementarity to lin-14. Cell. 1993 doi: 10.1016/0092-8674(93)90529-y. 


\section{JOURNAL of MEDICINE and LIFE}

9. Cretoiu D, Xu J, Xiao J, Suciu N, Cretoiu SM. Circulating MicroRNAs as Potential Molecular Biomarkers in Pathophysiological Evolution of Pregnancy. Dis Marker 2016; doi:10.1155/2016/3851054

10. Staicu CE, Predescu DV, Rusu CM, Radu BM, Cretoiu D, Suciu N, Crețoiu SM, Voinea SC. Role of microRNAs as Clinical Cancer Biomarkers for Ovarian Cancer: A Short Overview. Cells. 2020; doi:10.3390/cells9010169

11. Deftu AT, Radu BM, Cretoiu D, Deftu AF, Cretoiu SM, Xiao J. Exosomes as intercellular communication messengers for cardiovascular and cerebrovascular diseases. Exosomes. 2020. https://doi.org/10.1016/B978-0-12-816053-4.00009-2

12. Wang J, Chen J, Subrata S. MicroRNA as biomarkers and diagnostics. J. Cell. Physiol.2015.

https://doi.org/10.1002/jcp.25056

13. Khoury S, Tran N. Circulating microRNAs: Potential biomarkers for common malignancies. Biomarkers in Medicine. 2015. doi: 10.2217/bmm.14.102

14. Duică F, Condrat CE, Dănila CA, Boboc AE, Radu MR, Xiao J, Li X, Creţoiu SM, Suciu N, Creţoiu D, Predescu DV. MiRNAs: A Powerful Tool in Deciphering Gynecological Malignancies. Front Oncol. 2020 doi: 10.3389/fonc. 2020.591181 .

15. Bei Y, Tao L, Cretoiu D, Cretoiu SM, Xiao J. MicroRNAs Mediate Beneficial Effects of Exercise in Heart. Adv Exp Med Biol. 2017. doi: 10.1007/978-981-10-4304-8_15.

16. Gallo A, Tandon M, Alevizos I, Illei GG. The majority of microRNAs detectable in serum and saliva is concentrated in exosomes. PLoS One. 2012 doi:10.1371/journal.pone.0030679

17. Turchinovich A, Weiz L, Langheinz A, Burwinkel B. Characterization of extracellular circulating microRNA. Nucleic Acids Res. 2011. doi: 10.1093/nar/gkr254

18. Canfrán-Duque A, Lin CS, Goedeke L, Suárez Y, Fernández-Hernando C. Micro-RNAs and High-Density Lipoprotein Metabolism. Arterioscler Thromb Vasc Biol. 2016. doi: 10.1161/ATVBAHA.116.307028.

19. Vickers KC, Palmisano BT, Shoucri BM, Shamburek RD, Remaley AT. MicroRNAs are transported in plasma and delivered to recipient cells by high-density lipoproteins. Nat Cell Biol. 2011. doi: 10.1038/ncb2210.

20. Tabet F, Vickers KC, Cuesta Torres LF, Wiese CB, Shoucri BM, Lambert G, Catherinet C, Prado-Lourenco L, Levin MG, Thacker S, Sethupathy P, Barter PJ, Remaley AT, Rye KA. HDL-transferred microRNA-223 regulates ICAM-1 expression in endothelial cells. Nat Commun. 2014. expression in endothelial cell.
doi: 10.1038 /ncomms 4292

21. Wang K, Zhang S, Weber J, Baxter D, Galas DJ. Export of microRNAs and microRNA-protective protein by mammalian cells. Nucleic Acids Res. 2010; doi: $10.1093 / \mathrm{nar} / \mathrm{gkq} 601$.

22. Arroyo JD, Chevillet JR, Kroh EM, Ruf IK, Pritchard CC, Gibson DF, Mitchell PS, Bennett CF, Pogosova-Agadjanyan EL, Stirewalt DL, Tait JF, Tewari M. Argonaute2 complexes carry a population of circulating microRNAs independent of vesicles in human plasma. Proc. Natl. Acad. Sci. U. S. A.; 2011. 108 (12):5003-5008

23. Turchinovich A, Weiz L, Burwinkel B. Extracellular miRNAs: the mystery of their origin and function. Tren Biochem Sci. 2012. doi: 10.1016/j.tibs.2012.08.003

24. Condrat CE, Varlas VN, Duica F, Antoniadis P, Danila CA, Cretoiu D, Suciu N, Cretoiu SM, Voinea SC. Pregnancy - Related Extracellular Vesicles Revisited. Int. J. Mol. Sci. 2021. https://doi.org/10.3390/ijms22083904

25. Bei Y, Yu P, Cretoiu D, Cretoiu SM, Xiao J. Exosomes-Based Biomarkers for the Prognosis of Cardiovascular Diseases. Adv Exp Med Biol. 2017. doi: 10.1007/978-981-10-4397-0_5.

26. Cretoiu D, Xu J, Xiao J, Cretoiu SM. Telocytes and Thei Extracellular Vesicles-Evidence and Hypotheses. Int J Mol Sci. 2016. doi: 10.3390/ijms 17081322 .

27. Sanei M, Chen X. Mechanisms of microRNA turnover. Curr Opin Plant Biol. 2015. doi:10.1016/j. pbi.2015.07.008

28. Chen X, Ba Y, Ma L, Cai X, Yin Y, Wang K, Guo J, Zhang Y, Chen J, Guo X, Li Q, Li X, Wang W, Zhang Y, Wang J, Jiang X, Xiang Y, Xu C, Zheng P, Zhang J, Li R, Zhang H, Shang X, Gong T, Ning G, Wang J, Zen K, Zhang J, Zhang CY. Characterization of microRNAs in serum: a novel class of biomarkers for diagnosis of cancer and othe diseases. Cell Res. 2008. doi: 10.1038/cr.2008.282.
29. Cogswell JP, Ward J, Taylor IA, Waters M, Shi Y, Cannon B, Kelnar K, Kemppainen J, Brown D, Chen C, Prinjha RK, Richardson JC, Saunders AM, Roses AD, Richards CA Identification of miRNA changes in Alzheimer's disease brain and CSF yields putative biomarkers and insights into disease pathways. J Alzheimers Dis. 2008.

doi: $10.3233 /$ jad-2008-14103.

30. Zhou Q, Li M, Wang X, Li Q, Wang T, Zhu Q, Zhou $\mathrm{X}$, Wang X, Gao X, Li X. Immune-related microRNAs are abundant in breast milk exosomes. Int J Biol Sci. 2012. doi: $10.7150 /$ ijbs.8.118.

31. Weber JA, Baxter DH, Zhang S, Huang DY, Huang KH, Lee MJ, Galas DJ, Wang K. The microRNA spectrum in 12 Lee MJ, Galas DJ, Wang K. The
body fluids. Clin Chem. 2010. doi: 10.1373/clinchem.2010.147405.

32. da Silveira JC, Veeramachaneni DN, Winger QA, Carnevale EM, Bouma GJ. Cell-secreted vesicles in equine ovarian follicular fluid contain miRNAs and proteins: a possible new form of cell communication within the ovarian follicle. Biol Reprod. 2012. doi: 10.1095/biolreprod.111.093252.

33. Neagu M, Constantin C, Cretoiu SM, Zurac S. miRNA in the Diagnosis and Prognosis of Skin Cancer. Front Cell Dev Biol. 2020. doi: 10.3389/fcell.2020.00071.

34. Bei Y, Chen T, Banciu DD, Cretoiu D, Xiao J. Circulating Exosomes in Cardiovascular Diseases. Adv Exp Med Biol. 2017. doi: 10.1007/978-981-10-4397-0_17.

35. Iftikhar H, Carney GE. Evidence and potential in vivo functions for biofluid miRNAs: From expression profiling to functional testing: Potential roles of extracellular miRNAs as indicators of physiological change and as agents of intercellular information exchange. Bioessays. 2016 doi: 10.1002/bies.201500130.

36. Cretoiu SM. Circulating microRNAs in cardiovascular diseases: recent progress and challenges. J. Hypertens. Re 2016. 2(1):15-18

37. Foshay KM, Gallicano GI. Small RNAs, big potential: the role of MicroRNAs in stem cell function. Curr Stem Cell Res Ther. 2007. doi: 10.2174/157488807782793781.

38. Georgantas RW $3^{\text {rd }}$, Hildreth R, Morisot S, Alder J, Liu CG, Heimfeld S, Calin GA, Croce CM, Civin CI. CD34+ hematopoietic stem-progenitor cell microRNA expression and function: a circuit diagram of differentiation control. Proc Natl Acad Sci U S A. 2007. doi: 10.1073/pnas.0610983104.

39. Felli N, Fontana L, Pelosi E, Botta R, Bonci D, Facchiano F, Liuzzi F, Lulli V, Morsilli O, Santoro S, Valtieri M, Calin GA, Liu CG, Sorrentino A, Croce CM, Peschle C. MicroRNAs 221 and 222 inhibit normal erythropoiesis and erythroleukemic cell growth via kit receptor down-modulation. Proc Natl Acad Sci U S A. 2005. doi: $10.1073 /$ pnas. 0506216102 .

40. Fazi F, Rosa A, Fatica A, Gelmetti V, De Marchis ML, Nervi C, Bozzoni I. A minicircuitry comprised of microRNA-223 and transcription factors NFI-A and C/EBPalpha regulates human granulopoiesis. Cell. 2005. doi: 10.1016/j.cell.2005.09.023.

41. Chen CZ, Li L, Lodish HF, Bartel DP. MicroRNAs modulate hematopoietic lineage differentiation. Science. 2004. doi: 10.1126/science.1091903.

42. Krichevsky AM, Sonntag KC, Isacson O, Kosik KS Specific microRNAs modulate embryonic stem cell-derived neurogenesis. Stem Cells. 2006. doi: 10.1634/stemcells.2005-0441.

43. Anderson C, Catoe H, Werner R. MIR-206 regulates connexin 43 expression during skeletal muscle development. Nucleic Acids Res. 2006. doi: 10.1093/nar/gkl743.

44. Chen JF, Mandel EM, Thomson JM, Wu Q, Callis TE, Hammond SM, Conlon FL, Wang DZ. The role of microRNA-1 and microRNA-133 in skeletal muscle proliferation and differentiation. Nat Genet. 2006. doi: $10.1038 / \mathrm{ng} 1725$.

45. Roderburg C, Luedde T. Circulating microRNAs as markers of liver inflammation, fibrosis and cancer. J Hepatol. 2014. doi: 10.1016/j.jhep.2014.07.017.

46. Sohn W, Kim J, Kang SH, Yang SR, Cho JY, Cho HC, Shim SG, Paik YH. Serum exosomal microRNAs as novel biomarkers for hepatocellular carcinoma. Exp Mol Med. 2015. doi: $10.1038 / \mathrm{emm} .2015 .68$.

47 Pereira-da-Silva T, Coutinho Cruz M, Carrusca C, Cruz Ferreira R, Napoleão P, Mota Carmo M. Circulating microRNA profiles in different arterial territories of stable atherosclerotic disease: a systematic review. Am J Cardiovas Dis. 2018; 8(1):1-13.

48. Kehat I, Molkentin JD. Molecular pathways underlying cardiac remodeling during pathophysiological stimulation. Circulation. 2010.

https://doi.org/10.1161/CIRCULATIONAHA.110.942268

49. Navickas R, Gal D, Laucevičius A, Taparauskaite A, Zdanyte M, Holvoet P. Identifying circulating microRNAs as biomarkers of cardiovascular dos. Res.2016. https://doi.org/10.1093/cvr/cvw174

50. Huang X, Li Z, Bai B, Li X, Li Z. High expression of microRNA-208 is associated with cardiac hypertrophy via the negative regulation of the sex-determining region Y-box 6 protein. Exp Ther Med. 2015. doi: 10.3892/etm.2015.2645.

51. Ucar A, Gupta SK, Fiedler J, Erikci E, Kardasinski M, Batkai S, Dangwal S, Kumarswamy R, Bang C, Holzmann A, Remke J, Caprio M, Jentzsch C, Engelhardt S, Geisendorf S, Glas C, Hofmann TG, Nessling M, Richter K, Schiffer M, Carrier L, Napp LC, Bauersachs J, Chowdhury K, Thum T. The miRNA-212/132 family regulates both cardiac hypertrophy and cardiomyocyte autophagy. Nat. Commun. 2012. https://doi.org/10.1038/ncomms2090

52. Sygitowicz G, Tomaniak M, Błaszczyk O, Kołtowski Ł, Filipiak KJ, Sitkiewicz D. Circulating microribonucleic acids miR-1, miR-21 and miR-208a in patients with symptomatic heart failure: Preliminary results. Arch Cardiovasc Dis. 2015. heart failure: Preliminary results,

53. da Costa Martins PA, Salic K, Gladka MM, Armand AS, Leptidis S, el Azzouzi H, Hansen A, Coenen-de Roo CJ, Bierhuizen MF, van der Nagel R, van Kuik J, de Weger R, de Bruin A, Condorelli G, Arbones ML, Eschenhagen T, De Windt LJ. MicroRNA-199b targets the nuclear kinase Dyrk la in an auto-amplification loop promoting calcineurin/NFAT signalling. Nat Cell Biol. 2010. doi: 10.1038/ncb2126.

54. Karakikes I, Chaanine AH, Kang S, Mukete BN, Jeong D, Zhang S, Hajjar RJ, Lebeche D. Therapeutic cardiactargeted delivery of miR-1 reverses pressure overload-induced cardiac hypertrophy and attenuates pathological remodeling. J Am Heart Assoc. 2013 doi: 10.1161/JAHA 113.000078

55. Feng B, Chen S, George B, Feng Q, Chakrabarti S. miR 133a regulates cardiomyocyte hypertrophy in diabetes. Diabetes Metab Res Rev. 2010. doi: 10.1002/dmrr.1054.

56. Ganesan J, Ramanujam D, Sassi Y, Ahles A, Jentzsch C, Werfel S, Leierseder S, Loyer X, Giacca M, Zentilin L, Thum T, Laggerbauer B, Engelhardt S. MiR-378 controls cardiac hypertrophy by combined repression of mitogen-activated protein kinase pathway factors," Circulation. 2013. https://doi.org/10.1161/CIRCULATIONAHA.112.000882

57. Kim JO, Song DW, Kwon EJ, Hong SE, Song HK, Min CK, Kim DH. miR-185 plays an anti-hypertrophic role in the heart via multiple targets in the calcium-signaling pathways. PLoS One. 2015. doi: 10.1371/journal.pone.0122509.

58. Yang Y, Zhou Y, Cao Z, Tong XZ, Xie HQ, Luo T, Hua XP, Wang HO. miR-155 functions downstream of angiotensin II receptor subtype 1 and calcineurin to regulate cardiac hypertrophy. Exp Ther Med. 2016. doi: 10.3892/etm.2016.3506

59. Xin M, Olson EN, Bassel-Duby R. Mending broken hearts: cardiac development as a basis for adult heart regeneration and repair. Nat Rev Mol Cell Biol. 2013. doi: $10.1038 / \mathrm{nrm} 3619$.

60. Hulsmans M, Holvoet P. MicroRNA-containing microvesicles regulating inflammation in association with atherosclerotic disease. Cardiovasc Res. 2013. doi: $10.1093 / \mathrm{cvr} / \mathrm{cvt} 161$.

61. Jansen F, Yang X, Proebsting S, Hoelscher M, Przybilla D, Baumann K, Schmitz T, Dolf A, Endl E, Franklin BS, Sinning JM, Vasa-Nicotera M, Nickenig G, Werner N. MicroRNA expression in circulating microvesicles predicts cardiovascular events in patients with coronary artery disease. J Am Heart Assoc. 2014. doi: 10.1161/JAHA. 114.001249.

62. Jansen F, Yang X, Hoelscher M, Cattelan A, Schmitz T, Proebsting S, Wenzel D, Vosen S, Franklin BS, Fleischmann BK, Nickenig G, Werner N. Endothelial microparticle-mediated transfer of microRNA-126 promotes vascular endothelial cell repair via SPRED1 and is abrogated in glucose-damaged endothelial microparticles. Circulation. 2013. https://doi.org/10.1161/CIRCULATIONAHA.113.001720

63. Villar AV, García R, Merino D, Llano M, Cobo M, Montalvo C, Martín-Durán R, Hurlé MA, Nistal JF. Myocardial and circulating levels of microRNA-21 reflect left 


\section{JOURNAL of MEDICINE and LIFE}

ventricular fibrosis in aortic stenosis patients. Int J Cardiol. 2013. doi: 10.1016/j.ijcard.2012.07.021.

64. He X, Zhang K, Gao X, Li L, Tan H, Chen J, Zhou Y. Rapid atrial pacing induces myocardial fibrosis by down-regulating Smad7 via microRNA-21 in rabbit. Heart Vessels. 2016. doi: 10.1007/s00380-016-0808-z.

65. Li L, Ren S, Hao X, Zhen Z, Ji L, Ji H. MicroRNA-29b inhibits human vascular smooth muscle cell proliferation via targeting the TGF- $\beta /$ Smad3 signaling pathway. Exp Ther Med. 2021. doi: 10.3892/etm.2021.9923.

66. Pan Z, Sun X, Shan H, Wang N, Wang J, Ren J, Feng S, Xie L, Lu C, Yuan Y, Zhang Y, Wang Y, Lu Y, Yang B. MicroRNA-101 inhibited postinfarct cardiac fibrosis and improved left ventricular compliance via the FBJ osteosarcoma oncogene/transforming growth factor- $\beta 1$ osteosarcoma oncogene/tran
pathway. Circulation. 2012. pathway. Circulation. 2012.
doi: 10.1161/CIRCULATIONAHA. 112.094524.

67. Wang J, Huang W, Xu R, Nie Y, Cao X, Meng J, Xu X, Hu S, Zheng Z. MicroRNA-24 regulates cardiac fibrosis after myocardial infarction. J Cell Mol Med. 2012 doi: 10.1111/j.1582-4934.2012.01523.x.

68. Oka T, Akazawa H, Naito AT, Komuro I. Angiogenesis and cardiac hypertrophy: maintenance of cardiac function and causative roles in heart failure. Circ Res. 2014. doi: 10.1161/CIRCRESAHA.114.300507.

69. Bonauer A, Carmona G, Iwasaki M, Mione M, Koyanag M, Fischer A, Burchfield J, Fox H, Doebele C, Ohtani K, Chavakis E, Potente M, Tjwa M, Urbich C, Zeiher AM, Dimmeler S. MicroRNA-92a controls angiogenesis and Dimmeler S. MicroRNA-92a controls angiogenesis and
functional recovery of ischemic tissues in mice. Science. 2009. functional recovery of ischemic
doi: $10.1126 /$ science. 1174381 .

70. Fish JE, Santoro MM, Morton SU, Yu S, Yeh RF, Wythe JD, Ivey KN, Bruneau BG, Stainier DY, Srivastava D. miR-126 regulates angiogenic signaling and vascular integrity. Dev Cell. 2008. doi: 10.1016/j.devcel.2008.07.008.

71. Hu S, Huang M, Li Z, et al. MicroRNA-210 as a novel therapy for treatment of ischemic heart disease. Circulation. 2010. doi:10.1161/CIRCULATIONAHA.109.928424

72. Doebele C, Bonauer A, Fischer A, Scholz A, Reiss Y, Urbich C, Hofmann WK, Zeiher AM, Dimmeler S. Members of the microRNA-17-92 cluster exhibit a cell-intrinsic antiangiogenic function in endothelial cells. Blood, https://doi.org/10.1182/blood-2010-01-264812

73. Ohyagi-Hara C, Sawada K, Kamiura S, Tomita Y, Isobe A, Hashimoto K, Kinose Y, Mabuchi S, Hisamatsu T, Takahashi T, Kumasawa K, Nagata S, Morishige K, Lengyel E, Kurachi H, Kimura T. miR-92a inhibits peritoneal dissemination of ovarian cancer cells by inhibiting integrin a5 expression. Am J Pathol. 2013 doi: 10.1016/j.ajpath.2013.01.039.

74. Galluzzi L, Bravo-San Pedro JM, Vitale I, Aaronson SA, Abrams JM, Adam D, Alnemri ES, Altucci L, Andrews D, Annicchiarico-Petruzzelli M, Baehrecke EH, Bazan NG, Bertrand MJ, Bianchi K, Blagosklonny MV, Blomgren K, Borner C, Bredesen DE, Brenner C, Campanella M, Candi E, Cecconi F, Chan FK, Chandel NS, Cheng EH, Chipuk JE, Cidlowski JA, Ciechanover A, Dawson TM, Dawson VL, De Laurenzi V, De Maria R, Debatin KM, Dawson VL, De Laurenzi , De Maria R, Debatin KM,
Di Daniele N, Dixit VM, Dynlacht BD, El-Deiry WS, Di Daniele N, Dixit VM, Dynlacht BD, El-Deiry WS,
Fimia GM, Flavell RA, Fulda S, Garrido C, Gougeon ML, Green DR, Gronemeyer H, Hajnoczky G, Hardwick JM, Hengartner MO, Ichijo H, Joseph B, Jost PJ, Kaufmann T, Kepp O, Klionsky DJ, Knight RA, Kumar S, Lemasters IJ. Levine B, Linkermann A, Lipton SA, Lockshin RA, López-Otín C, Lugli E, Madeo F, Malorni W, Marine JC, Martin SJ, Martinou JC, Medema JP, Meier P, Melino S, Mizushima N, Moll U, Muñoz-Pinedo C, Nuñez G, Oberst A, Panaretakis T, Penninger JM, Peter ME, Piacentini M, Pinton P, Prehn JH, Puthalakath H, Rabinovich GA M, Pinton P, Prehn JH, Puthalakath H, Rabinovich GA,
Ravichandran KS, Rizzuto R, Rodrigues CM, Rubinsztein DC, Rudel T, Shi Y, Simon HU, Stockwell BR, Szabadkai G, Tait SW, Tang HL, Tavernarakis N, Tsujimoto Y, Vanden Berghe T, Vandenabeele P, Villunger A, Wagner EF, Walczak H, White E, Wood WG, Yuan J, Zakeri Z, Zhivotovsky B,
Melino G, Kroemer G. Essential versus accessory aspects of cell death: recommendations of the NCCD 2015. Cell Death Differ. 2015. doi: 10.1038/cdd.2014.137.

75. Xiong H, Luo T, He W, Xi D, Lu H, Li M, Liu J, Guo Z. Up-regulation of miR-138 inhibits hypoxia-induced cardiomyocyte apoptosis via down-regulating lipocalin-2 expression. Exp Biol Med (Maywood). 2016. doi: $10.1177 / 1535370215591831$.

76. Wang H, Li J, Chi H, Zhang F, Zhu X, Cai J, Yang X. MicroRNA-181c targets Bcl-2 and regulates mitochondrial morphology in myocardial cells. J Cell Mol Med. 2015. doi: $10.1111 /$ jcmm. 12563 .

77. Yang Q, Yang K, Li A. microRNA-21 protects agains ischemia-reperfusion and hypoxia-reperfusion-induced cardiocyte apoptosis via the phosphatase and tensin homolog/Akt-dependent mechanism. Mol Med Rep. 2014. doi: $10.3892 / \mathrm{mmr} .2014 .2068$.

78. Roca-Alonso L, Castellano L, Mills A, Dabrowska AF Sikkel MB, Pellegrino L, Jacob J, Frampton AE, Krell J, Coombes RC, Harding SE, Lyon AR, Stebbing J. Myocardial MiR-30 downregulation triggered by doxorubicin drives alterations in $\beta$-adrenergic signaling and enhances apoptosis. Cell Death Dis. 2015. doi: 10.1038/cddis.2015.89.

79. Li H, Fan J, Yin Z, Wang F, Chen C, Wang DW. Identification of cardiac-related circulating microRNA profile in human chronic heart failure. Oncotarget. 2016. in human chronic heart failure. 10.18632 /oncotarget.6631.

80. Malik R, Mushtaque RS, Siddiqui UA, Younus A, Aziz MA, Humayun C, Mansoor K, Latif MA, Waheed S, Assad S, Khan I, Bukhari SM, DelCampo D, Adus A, Gannarapu S, Khan I, Bukhari SM, DelCampo D, Adus A, Ganna
S. Association Between Coronary Artery Disease and S. Association Between Coronary Artery Disease and
MicroRNA: Literature Review and Clinical Perspective. Cureus. 2017. doi: 10.7759/cureus. 1188 .

81. Fortea JI, Puente Á, Cuadrado A, Huelin P, Pellón R, González Sánchez FJ, Mayorga M, Cagigal ML, García Carrera I, Cobreros M, Crespo J, Fábrega E. Congestive Hepatopathy. Int J Mol Sci. 2020. doi: $10.3390 /$ ijms21249420.

82. Hu J, Xu Y, Hao J, Wang S, Li C, Meng S. MiR-122 in hepatic function and liver diseases. Protein Cell. 2012. doi: $10.1007 / \mathrm{s} 13238-012-2036-3$

83. Tsai WC, Hsu SD, Hsu CS, Lai TC, Chen SJ, Shen R, Huang Y, Chen HC, Lee CH, Tsai TF, Hsu MT, Wu JC, Huang HD, Shiao MS, Hsiao M, Tsou AP. Wu JC, Huang HD, Shiao MS, Hsiao M, Tsou AP.
MicroRNA-122 plays a critical role in liver homeostasis and MicroRNA-122 plays a critical role in liver
hepatocarcinogenesis. J Clin Invest. 2012 . doi: 10.1172/JCI63455.

84. Hsu SH, Wang B, Kutay H, Bid H, Shreve J, Zhang X, Costinean S, Bratasz A, Houghton P, Ghoshal K. Hepatic loss of miR-122 predisposes mice to hepatobiliary cyst and hepatocellular carcinoma upon diethylnitrosamine exposure. Am J Pathol. 2013. doi: 10.1016/j.ajpath.2013.08.004.

85. Abu-Halima M, Meese E, Saleh MA, Keller A, Abdul-Khaliq H, Raedle-Hurst T. MicroRNA-29b/c-3p Indicate Advanced Liver Fibrosis/Cirrhosis in Univentricula Heart Patients With and Without Fontan Palliation. Front Cardiovasc Med. 2021. doi: 10.3389/fcrm.2020.619083.

86. Ellis KL, Cameron VA, Troughton RW, Frampton CM, Ellmers LJ, Richards AM. Circulating microRNAs as candidate markers to distinguish heart failure in breathless patients. Eur J Heart Fail. 2013. doi: 10.1093/eurjhf/hft078. 87. Corsten MF, Dennert R, Jochems S, Kuznetsova T, Devaux Y, Hofstra L, Wagner DR, Staessen JA, Heymans S, Schroen B. Circulating MicroRNA-208b and MicroRNA-499 reflect myocardial damage in cardiovascular disease. Circ
Cardiovasc Genet. 2010

doi: 10.1161/CIRCGENETICS. 110.957415

88. Vegter EL, van der Meer P, de Windt LJ, Pinto YM, Voors AA. MicroRNAs in heart failure: from biomarker to target for therapy. Eur J Heart Fail. 2016. doi: 10.1002/ejhf.495.

89. Tijsen AJ, Creemers EE, Moerland PD, de Windt LJ, van der Wal AC, Kok WE, Pinto YM. MiR423-5p as a circulating biomarker for heart failure. Circ Res. 2010. doi: 10.1161/CIRCRESAHA. 110.218297.

90. Watson CJ, Gupta SK, O'Connell E, Thum S, Glezeva N, Fendrich J, Gallagher J, Ledwidge M, Grote-Levi L, McDonald K, Thum T. MicroRNA signatures differentiate preserved from reduced ejection fraction heart failure. Eur $J$ preserved from reduced ejection fraction

91. Wong LL, Armugam A, Sepramaniam S, Karolina DS, Lim KY, Lim JY, Chong JP, NgJY, Chen YT, Chan MM, Chen Z, Yeo PS, Ng TP, Ling LH, Sim D, Leong KT Ong HY, Jaufeerally F, Wong R, Chai P, Low AF, Lam CS, Jeyaseelan K, Richards AM. Circulating microRNAs in heart failure with reduced and preserved left ventricular ejection fraction. Eur J Heart Fail. 2015. doi: 10.1002/ejhf.223.

92. Qiang L, Hong L, Ningfu W, Huaihong C, Jing W. Expression of miR-126 and miR-508-5p in endothelial progenitor cells is associated with the prognosis of chronic heart failure patients. Int J Cardiol. 2013.

doi: $10.1016 /$ j.ijcard.2013.01.160

93. Ovchinnikova ES, Schmitter D, Vegter EL, Ter Maaten JM, Valente MA, Liu LC, van der Harst P, Pinto YM, de Boer RA, Meyer S, Teerlink JR, O'Connor CM, Metra M, Davison BA, Bloomfield DM, Cotter G, Cleland JG, M, Davison BA, Bloomfield DM, Cotter G, Cleland JG,
Mebazaa A, Laribi S, Givertz MM, Ponikowski P, van der Meer P, van Veldhuisen DJ, Voors AA, Berezikov E. Signature of circulating microRNAs in patients with acute heart failure. Eur J Heart Fail. 2016. doi: 10.1002/ejhf.332.

94. Zhou Y, Deng L, Zhao D, Chen L, Yao Z, Guo X, Liu X, Lv L, Leng B, Xu W, Qiao G, Shan H. MicroRNA-503 promotes angiotensin II-induced cardiac fibrosis by targeting Apelin-13. J Cell Mol Med. 2016. doi: 10.1111/jcmm.12754.

95. Sygitowicz G, Maciejak-Jastrzębska A, Sitkiewicz D. MicroRNAs in the development of left ventricular remodeling and postmyocardial infarction heart failure. $\mathrm{Pol}$ Arch Intern Med. 2020. doi: 10.20452/pamw.15137.

96. Marfella R, Di Filippo C, Potenza N, Sardu C, Rizzo MR, Siniscalchi M, Musacchio E, Barbieri M, Mauro C, Mosca N, Solimene F, Mottola MT, Russo A, Rossi F, Paolisso G, D'Amico M. Circulating microRNA changes in heart failure patients treated with cardiac resynchronization therapy: responders vs. non-responders. Eur J Heart Fail. 2013. doi: 10.1093/eurjhf/hft088.

97. Elzenaar I, Pinto YM, Van Oort RJ. MicroRNAs in heart failure: New targets in disease management. Clinical Pharmacology and Therapeutics. 2013. https://doi.org/10.1038/clpt.2013.138

98. Kalampogias A, Siasos G, Oikonomou E, Mourouzis K, Bletsa E, Stampouloglou PK, Katsianos E, Vlasis K, Marinos G, Charalambous G, Vavouranakis M, Tousoulis D. MicroRNAs in the Management of Heart Failure. Curr Med Chem. 2021. doi: 10.2174/0929867328666210218181441. 